\title{
Study on dynamic load-sharing characteristics of face gear dual-power split transmission system with backlash, support and spline clearance
}

\author{
Hao Dong ${ }^{1}$, Hao Qin Zhang ${ }^{1}$, Xiao Long Zhao ${ }^{1}$, and Ling Ling Duan ${ }^{2}$ \\ ${ }^{1}$ School of Mechatronic Engineering, Xi' an Technological University, Xi' an 710021, China \\ ${ }^{2}$ Shaanxi Hualu Chemical Green Environmental Protection Co., Ltd., Xi' an 710025, China \\ Correspondence: Hao Dong (donghao@xatu.edu.cn)
}

Received: 4 December 2020 - Revised: 12 April 2021 - Accepted: 22 April 2021 - Published: 25 May 2021

\begin{abstract}
The dynamic load-sharing characteristics of aircraft face gear dual-power split transmission system (FGDPSTS) are taken as the research object. Considering the factors of time-varying meshing stiffness, comprehensive error, backlash, support clearance, spline clearance, torsional stiffness, and support stiffness, the dynamic load-sharing model was constructed based on the lumped-parameter method. The loaded tooth contact analysis (LTCA) simulation method was used to calculate the time-varying meshing stiffness. The dynamic load-sharing coefficient (DLSC) is obtained by using Runge-Kutta method. The influences of errors, backlash, support clearance, spline clearance, torsional stiffness and support stiffness on DLSC were analyzed, and the biggest factors affecting dynamic load-sharing performance were found out. The results show that the influence of the backlash of the two-stage herringbone gear pair on the DLSC is more sensitive. The influence of support clearance on the DLSC is less. The load-sharing coefficient increases with the increase of the installation error and eccentricity error, and the influence of the error of the two-stage gears on the system load-sharing performance is the most sensitive. The torsional stiffness has little effect on the load-sharing coefficient of one stage but has great effect on the two-stage load-sharing coefficient. The influence of support stiffness on the DLSC of two-stage is stronger. It provided a theoretical basis for the dynamic stability optimization design of the system.
\end{abstract}

The face gear transmission system (Heath and Bossler, 1993; Handschuh et al., 1996) replaces the original bevel gear transmission on the third-generation Apache armed helicopter. Compared with the bevel gear transmission, the face gear is used in the one-stage transmission, which has a good power-splitting effect, and can realize the reversing and splitting at the same time. The number of transmission stages is reduced from four to three stages, the weight of the transmission system is reduced by $40 \%$, and the bearing capacity is increased by $35 \%$. The support structure of spiral bevel gear is complex, and the pinion driven by face gear is not subject to axial force, which is conducive to reducing weight and noise, improving reliability and service life.

Many researchers at home and abroad have done a lot of research on gear-related theory and load-sharing technology.
Krantz (1996a, b) has done further research on the load sharing of the two branches of the cylindrical gear. By defining the synchronous angle, the influence on the load-sharing performance of the power split transmission is studied, and the mathematical relationship between the same step angle and load-sharing coefficient is tested and verified. Robert and James (2006) proposed applying the face gear to a configuration similar to the planetary gear transmission. Using two face gears with the same axis, the face gear on the input shaft and the small gear mesh, the small gear on the other end of the coaxial gear and a fixed rotating face gear mesh, the small gear shaft is installed on the output shaft. Stevens et al. (2009) put forward the variable speed configuration of the fixed axis star gear and face gear. The face gear is used to replace the fixed axis star gear on the transmission chain. The face gear is designed as an idler gear to achieve the same high- and low-speed output steering of the 
transmission system. Because the input and output shafts of the face gear are installed in the same axis, the structure is tight and the commutation is more stable. Peng et al. (2016) take the coaxial face gear transmission system as the research object, establish the geometric model and kinematic model of the face gear transmission, study the parameter instability of the face gear transmission, and analyze the load distribution characteristics of the coaxial face gear transmission system under different working speeds. Jin et al. (2019a, b) considered the backlash, the time-varying meshing stiffness between the gear pairs, the gear eccentricity error, the shaft torsion and the support stiffness and constructed the dynamic model of the face gear cylindrical gear two power split transmissions, focusing on the influence of the torsional stiffness of each transmission shaft on the load-sharing coefficient of the system. Mo et al. (2020) established the bending torsional coupling dynamic load-sharing model of multi-power input face gear branch transmission system and studied the influence of meshing phase and error on the load-sharing coefficient. Dong et al. (2019) analyzed the assembly, power flow and load sharing of the coaxial face gear split torsional transmission system, deduced the assembly and installation conditions suitable for the coaxial face gear split torsional transmission system, and studied the power distribution direction of the system through the finite element method, and analyzed the influence of load conditions, distribution angle and installation angle. Wang et al. (2013) studied the influence of the dynamic load-sharing characteristics of the face gear split torsional transmission system. Bao et al. (2019) studied the load-sharing and dynamic characteristics of the variable speed helicopter transmission system and analyzed the influence of input power, input speed and friction factor on the load-sharing and dynamic characteristics of the system. Wang et al. (2019) studied the load-sharing performance of the two-branching cylindrical gear split torsional transmission system and analyzed the influence of working conditions, torsional stiffness, support stiffness, meshing phase difference and other factors on the load-sharing performance of the system. Zhang and Zhu (2018) studied the static loadsharing characteristics of a herringbone planetary gear system with floating combined inner gear ring and qualitatively analyzed the influence of the eccentricity error of each component, the floating mode and floating amount of the central component, the torsional rigidity of the flexible inner gear ring and other parameters on the static load-sharing characteristics of the system.

In previous studies, the influence of backlash and support clearance on the load-sharing characteristics of face gear drive is seldom considered, and the average mesh stiffness is mostly used in the establishment and calculation of the model, which cannot fully reflect the influence of the meshing process of tooth surface on the dynamic load-sharing characteristics of the system. According to the structure layout and transmission characteristics of the helicopter main reducer, and the advantages of two branch power split trans- mission of face gear, a face gear dual-power split transmission system configuration with dual-power split characteristics is proposed. Based on the lumped-parameter method, the dynamic model of the system is constructed, the dynamic differential equation is derived, the dynamic load-sharing coefficient (DLSC) is obtained, and the influence of parameters on the DLSC is analyzed. It provides the theoretical basis for the dynamic vibration stability optimization design of the face gear dual-power split transmission system.

\section{Transmission system configuration and dynamic model establishment}

Figure 1 is the configuration diagram of the face gear dualpower split transmission system (FGDPSTS), with the technical characteristics of one-stage face gear pair power split, two-stage pinion secondary power split, two-stage idler gear convergence, two-stage gear output. Compared with the face gear two-branch transmission system implemented by an art program of the United States (Handschuh et al., 1996), this configuration adopts a two-stage split twist layout to meet the requirements of a large transmission ratio, high power density ratio and large thrust weight ratio. The transmission power of the gear is divided by multiple channels, and the torque transmitted by the gears in each branch is reduced, so that the bearing capacity of the gear is improved, and the service life and reliability of the system are further improved.

Figure 2 shows the torsional dynamic model of this system.

Here, $T_{\text {in }}$ and $T_{\text {out }}, k_{\text {in }}$ and $k_{\text {out }}$, and $c_{\text {in }}$ and $c_{\text {out }}$ are the input torque and output torque, torsional stiffness and torsional damping of input and output shafts, respectively. $\varphi_{\text {in }}$ and $\varphi_{\text {out }}, m_{\text {in }}$ and $m_{\text {out }}$, and $I_{\text {in }}$ and $I_{\text {out }}$ are the torsion angle, equivalent lumped mass and moment of inertia of prime mover and loaded, respectively. $k_{i j}, c_{i j}, e_{(t) i j}$ and $b_{i j}$ are the time-varying meshing stiffness, meshing damping, comprehensive error and backlash of each gear pair $i j$, respectively. $\varphi_{i z}$ is the torsional vibration micro-displacement of each gear i. $m_{i}$ is the equivalent concentrated lumped-mass gear $i . I_{i}$ is the moment of inertia of component $i . k_{24}$ and $k_{35}$ and $c_{24}$ and $c_{35}$ are the torsional stiffness and torsional damping of connecting shaft 24 and connecting shaft 35 .

The dynamic model of one-stage face gear is established as shown in Fig. 3. $k_{x i}$ and $k_{y i}$ are the support stiffness in $x$ direction and $y$ direction of gear $i$, respectively. $c_{x i}$ and $c_{y i}$ are the support damping in $x$ direction and $y$ direction of gear $i$, respectively. $b_{i j}$ is the average meshing backlash. $b_{d i}$ is the average elastic clearance. The input spur gear coordinate system is $O_{1} x_{1} y_{1} z_{1}$. The face gear coordinate system is $O_{2} x_{2} y_{2} z_{2}$ and $O_{3} x_{3} y_{3} z_{3}$, respectively. The $z$ axis is the vertical upward axial direction of the face gear. The input gear shaft is perpendicular to the $x$ direction, $y$ direction and $x z$ plane. 


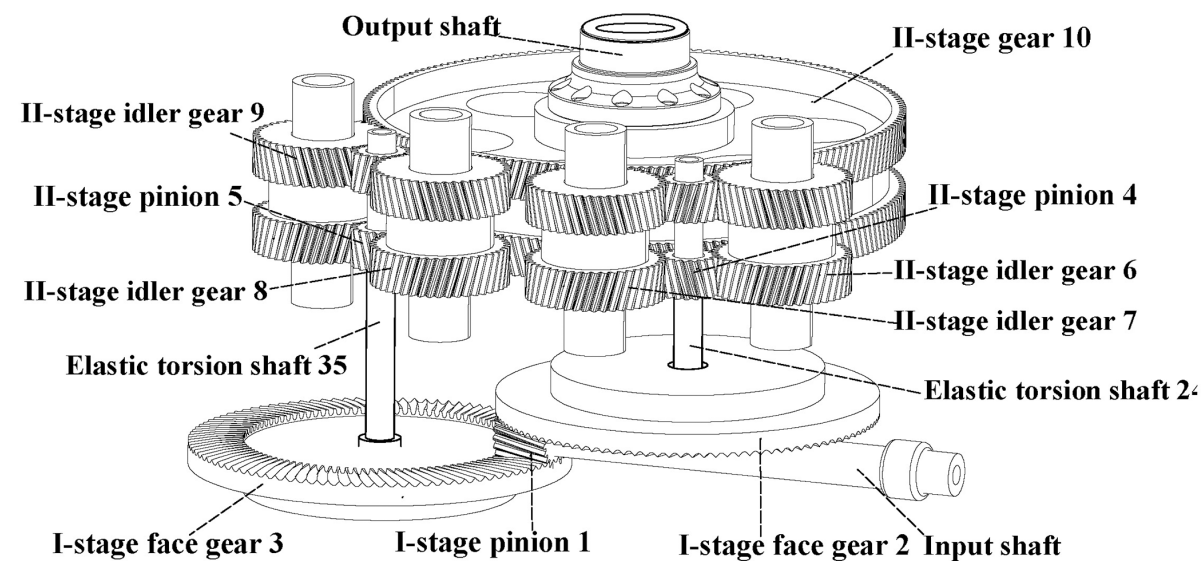

Figure 1. Schematic diagram of the FGDPSTS.

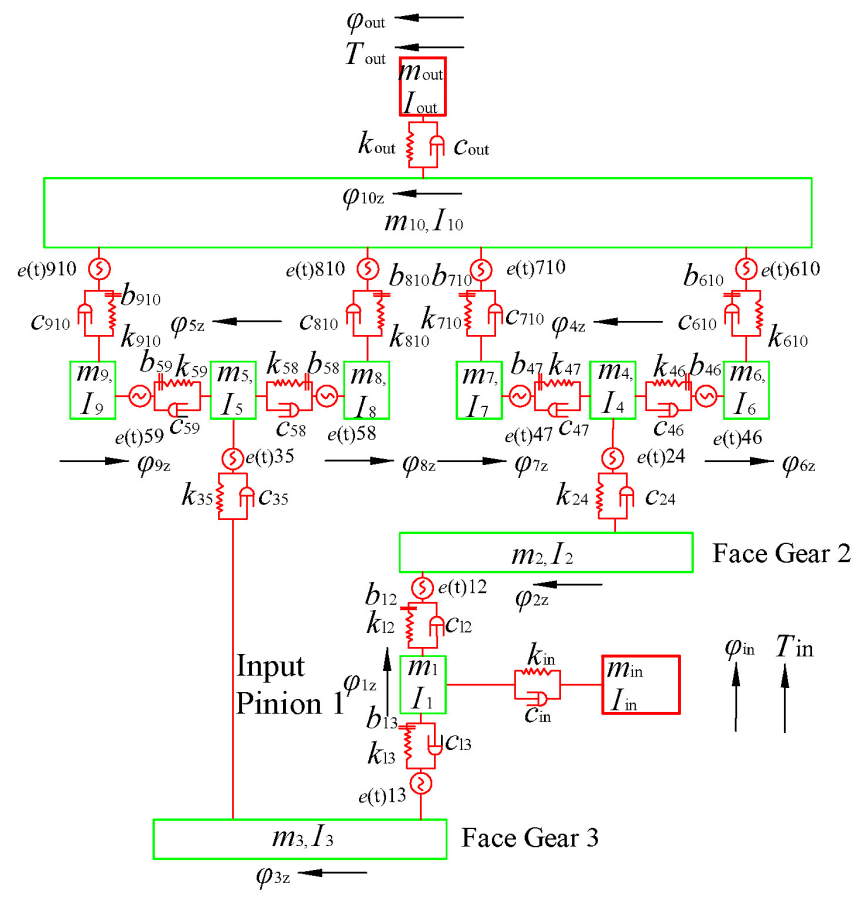

Figure 2. Torsional dynamic model of the system.

The generalized vibration displacement vector $\delta$ with 32 degrees of freedom can be expressed as Eq. (1). Here, $x_{i}, y_{i}$ and $z_{i}$ are the transverse bending deformation of each gear in the $x$ direction, $y$ direction and $z$ direction, respectively. $\varphi_{i z}$, $\varphi_{\text {in }}$ and $\varphi_{\text {out }}$ are the torsional angular displacement of gear $i$, prime mover and load components.

$$
\begin{aligned}
\delta= & \left\{z_{1}, z_{2}, z_{3}, x_{4}, \ldots, x_{10}, y_{1}, y_{2}, \ldots, y_{10}, \varphi_{\text {in }},\right. \\
& \left.\varphi_{1 y}, \varphi_{2 z}, \varphi_{3 z}, \ldots, \varphi_{10 z}, \varphi_{\text {out }}\right\}
\end{aligned}
$$

Force analysis of the one-stage face gear pair is shown in Fig. 4.
Here, $r_{1}$ is the pitch radius. $r_{a 1}$ is the top circle radius. The vibration displacement of pinion $O_{1}$ is $y_{1}$ and $z_{1}$ along $y$ direction and $z$ direction, respectively. The vibration displacement of face gear $O_{2}$ and $O_{3}$ along $y$ direction and $z$ direction is $y_{2}, y_{3}$ and $z_{2}, z_{3}$, respectively.

The meshing forces of $F_{12}$ and $F_{13}$ can be expressed as follows:

$\left\{\begin{array}{l}F_{12 x}=0, F_{12 y}=F_{12} \cos \alpha_{12}, F_{12 z}=F_{12} \sin \alpha_{12}, \\ F_{13 x}=0, F_{13 y}=F_{13} \cos \alpha_{13}, F_{13 z}=F_{13} \sin \alpha_{13}\end{array}\right.$.

\section{Establishment of differential equations of system dynamics}

Based on the lumped-parameter method, the torsional vibration dynamic equation of the system is established as follows:

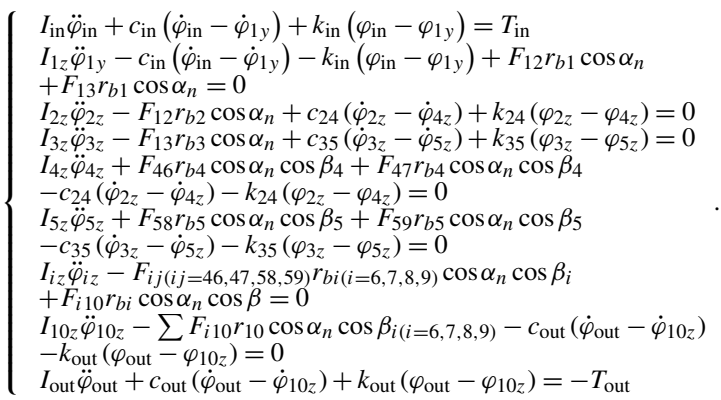

Here, $\ddot{\varphi}_{i z}, \ddot{\varphi}_{\text {in }}$ and $\ddot{\varphi}_{\text {out }}$ are the angular acceleration of torsional vibration corresponding to gear $i$, prime mover and load component. $\dot{\varphi}_{i z}, \dot{\varphi}_{\text {in }}$ and $\dot{\varphi}_{\text {out }}$ are the angular velocity of torsional vibration corresponding to gear $i$, prime mover and load component. $r_{b i}$ represents the radius of base circle of gear $i$, where $r_{b 2}$ and $r_{b 3}$ represent the radius of base circle of face gear, $r_{b 2}=r_{b 3}=\left(r_{L 1}+r_{L 2}\right)$, and $r_{L 1}$ is the inner radius of the face gear determined by the undercutting condition, and $r_{L 2}$ is the outer radius of the face gear determined by the tip sharpening condition. $I_{i}(i=1,2, \ldots, 10)$ is the moment of inertia of each component. $\alpha_{n}$ is the normal meshing pressure angle of gear pair meshing. 


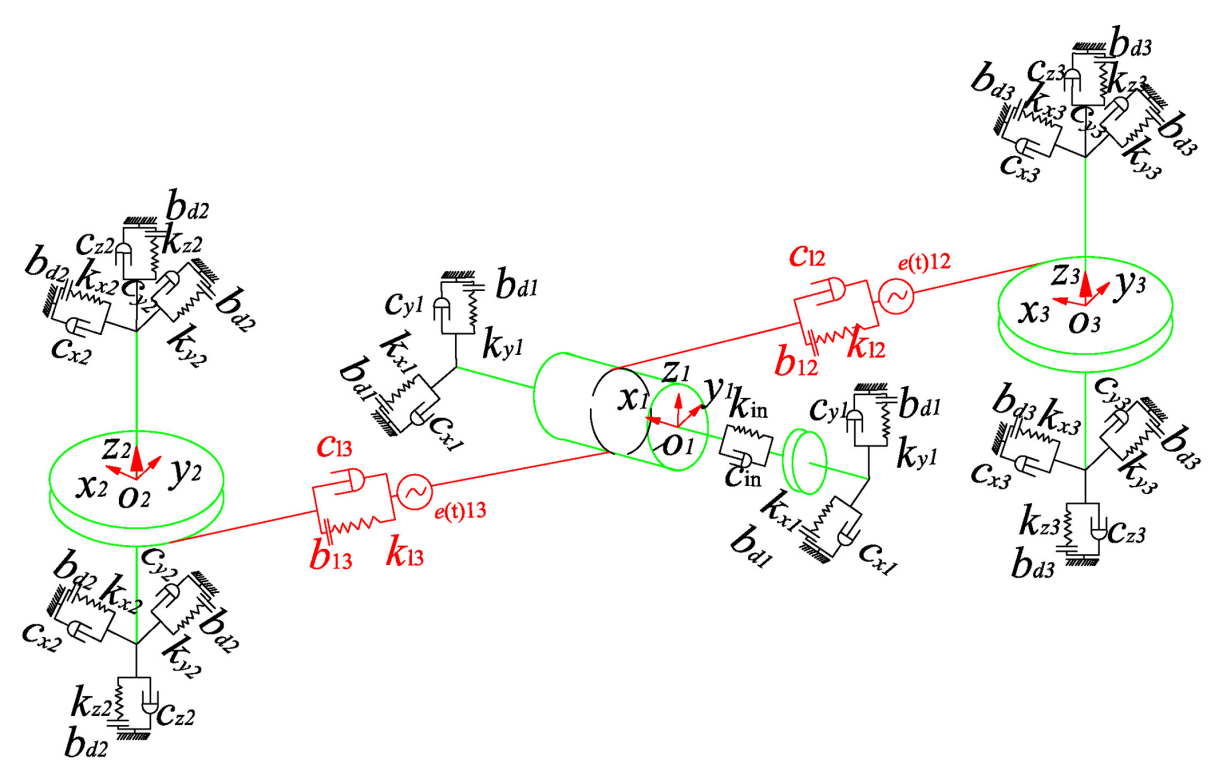

Figure 3. Dynamic model of the one-stage face gear.

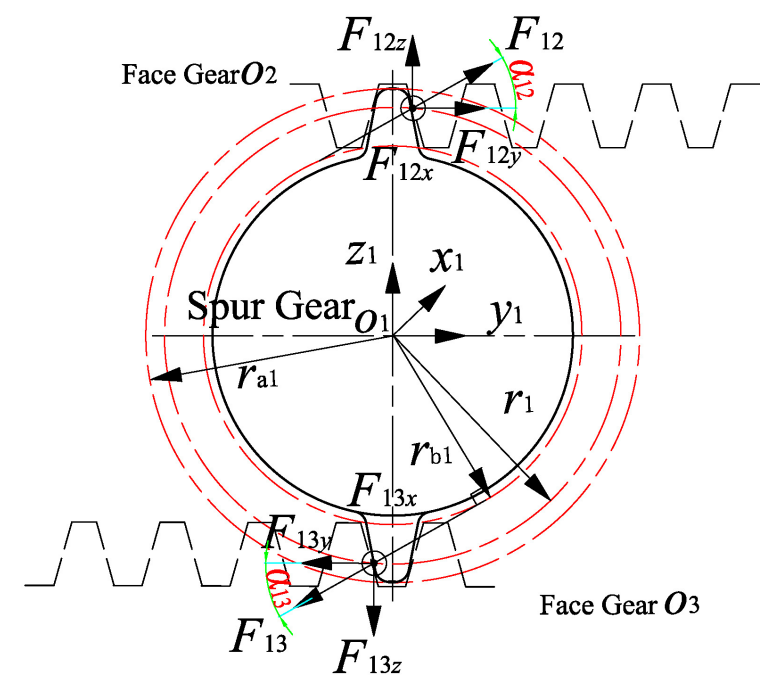

Figure 4. Schematic diagram of the force distribution of the face gear pair.

The angular displacement form is transformed into the linear displacement form, which can be expressed as $\ddot{u}_{i}=$ $r_{b i} \ddot{\varphi}_{i z}, \dot{u}_{i}=r_{b i} \dot{\varphi}_{i z}, u_{i}=r_{b i} \varphi_{i z}$. The mass $m_{\mathrm{eq}, i}$ can be expressed as $m_{\mathrm{eq}, i}=I_{i} / r_{b i}^{2}$.

The expressions of torsional damping $c_{24}$ and $c_{35}$ are as follows:

$$
\left\{\begin{array}{l}
c_{24}=2 \zeta_{24} \sqrt{k_{24} /\left(1 / I_{2}+1 / I_{4}\right)} \\
c_{35}=2 \zeta_{35} \sqrt{k_{35} /\left(1 / I_{3}+1 / I_{5}\right)}
\end{array}\right.
$$

Here, $\zeta_{24}$ and $\zeta_{35}$ are the damping coefficients.
Based on Newton's second law, the lateral vibration equation of the system is established as follows:

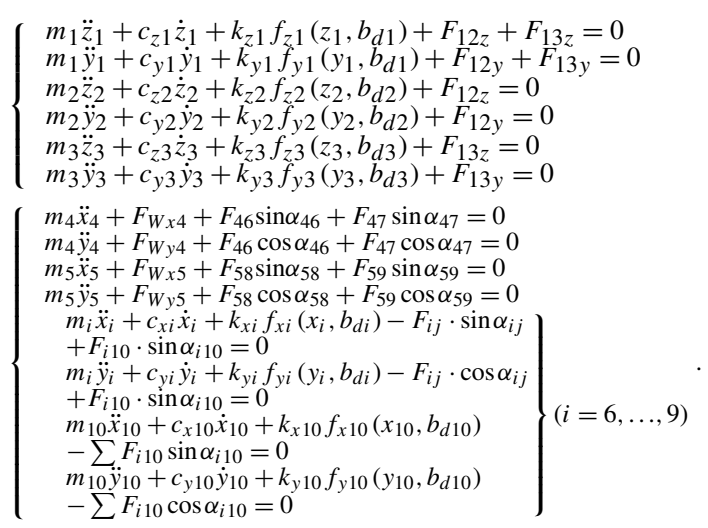

Here, $\ddot{x}_{i}, \dot{x}_{i}$ and $x_{i}$ are the lateral $x$-direction vibration acceleration, velocity and displacement, respectively. $\ddot{y}_{i}, \dot{y}_{i}$ and $y_{i}$ are the lateral $y$-direction vibration acceleration, velocity and displacement, respectively. $\ddot{z}_{i}, \dot{z}_{i}$ and $z_{i}$ are the lateral $z$ direction vibration acceleration, velocity and displacement, respectively.

$F_{W x i}$ and $F_{W y i}$ of gear $i(i=4,5)$ are the component of the supporting force of the spline shaft in $x$ and $y$ directions. Taking pinion $O_{4}$ as an example, the dynamic mechanical analysis model is shown in Fig. 5.

$k_{w x i}$ and $k_{w y i}$ as well as $c_{w x i}$ and $c_{w y i}$ are bending stiffness and bending damping of spline shaft in $x$ and $y$ directions. $F_{m}=\tau F_{N}$ is the friction force between the internal and external splines in the process of transmitting torque. $F_{N}$ represents the normal positive pressure between the internal and external splines. $\tau$ is the coefficient of friction. $\tau=\tau_{0} \cdot \operatorname{sgn}\left(v_{\mathrm{s}}\right), \tau_{0}$ is the amplitude of friction coefficient, $v_{\mathrm{s}}$ 


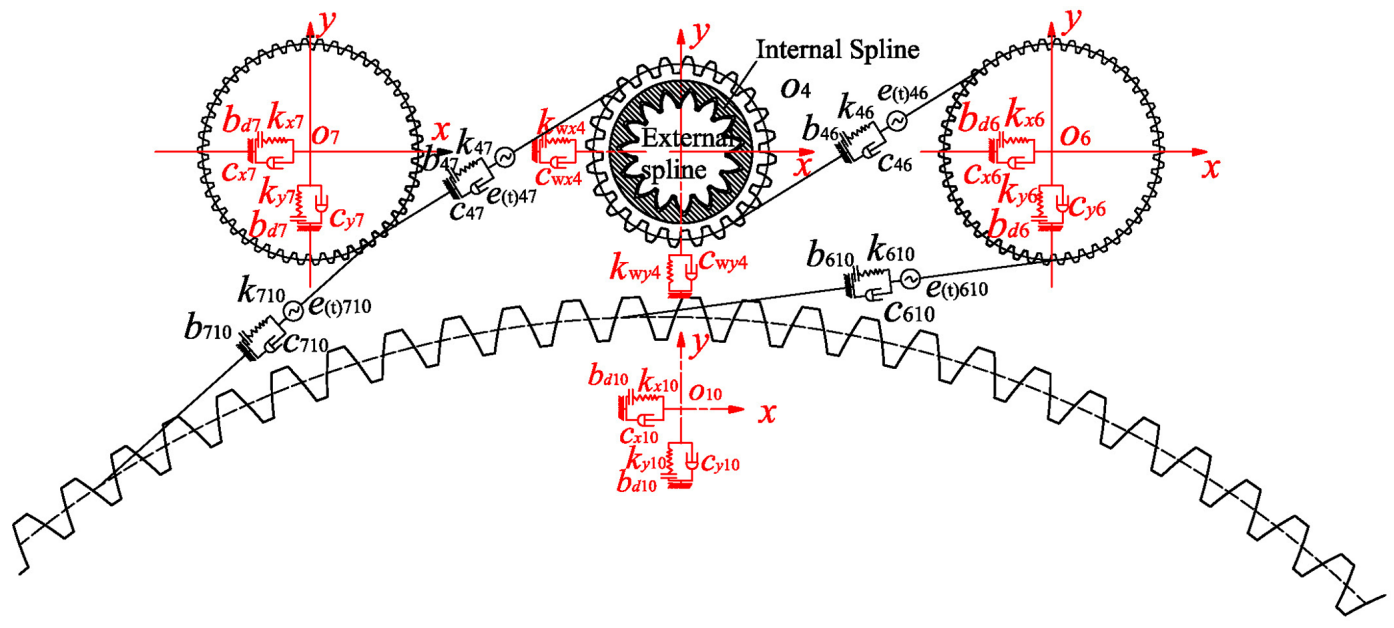

Figure 5. Dynamics model of the two-stage pinion $\mathrm{O}_{4}$ under the supporting action of spline shaft.

is the relative sliding speed, and $\operatorname{sgn}\left(v_{\mathrm{S}}\right)$ is the symbol function of $v_{\mathrm{s}}$. Here, $\tau_{0}=0.1, \operatorname{sgn}\left(v_{\mathrm{s}}>0\right)=1, \tau=0.1$.

Comprehensive displacement of gear $i(i=4,5)$ in $x$ direction and $y$ direction can be expressed as $R_{i}=\sqrt{x_{i}^{2}+y_{i}^{2}}$. $R_{i}$ is the total displacement and also represents the value of spline.

The lateral bending supporting forces $F_{W x i}$ and $F_{W y i}$ can be described as follows:

$$
\begin{gathered}
F_{W x i}=\left\{\begin{array}{l}
-c_{w x i} \dot{R}_{i} \cos \left(\xi_{i}\right)-k_{w x i} R_{i} \cos \left(\xi_{i}\right) \quad 0 \leq R_{i}<\mathrm{S}_{1} \\
-c_{m} \cos \left(\xi_{i}\right)-F_{m} \cos \left(\xi_{i}\right) \quad S_{1} \leq R_{i} \leq \mathrm{S}_{2} \\
-\left(c_{m}+c_{w x i} \dot{R}_{i}\right) \cdot \cos \left(\xi_{i}\right) \\
-\left(F_{m}+k_{w x i}\left(R_{i}-\mathrm{S}_{2}\right)\right) \cos \left(\xi_{i}\right) \quad R_{i}>\mathrm{S}_{2}
\end{array}\right. \\
F_{W y i}= \begin{cases}-c_{w y i} \dot{R}_{i} \sin \left(\xi_{i}\right)-k_{w y i} R_{i} \sin \left(\xi_{i}\right) & 0 \leq R_{i}<\mathrm{S}_{1} \\
-c_{m} \sin \left(\xi_{i}\right)-F_{m} \sin \left(\xi_{i}\right) \quad S_{1} \leq R_{i} \leq \mathrm{S}_{2} \\
-\left(c_{m}+c_{w y i} \dot{R}_{i}\right) \sin \left(\xi_{i}\right) & \\
-\left(F_{m}+k_{w y i}\left(R_{i}-\mathrm{S}_{2}\right)\right) \sin \left(\xi_{i}\right) & R_{i}>\mathrm{S}_{2}\end{cases}
\end{gathered}
$$

Here, $c_{m}$ is friction damping. $S_{1}$ and $S_{2}$ are the radial clearance of internal and external splines. $\xi_{i}$ is direction angle of vector $\left(x_{i}, y_{i}\right)$. By combining the differential equations of dynamic torsion and transverse vibration mentioned above, the bending-torsion coupled non-linear dynamic differential equations can be obtained.

\section{DLSC calculation}

The backlash $f_{i j}\left(x_{i j}, b_{i j}\right)$ and support clearance $f_{x i}\left(x_{i}, b_{d i}\right)$, $f_{y i}\left(y_{i}, b_{d i}\right)$ and $f z_{i}\left(z_{i}, b_{d i}\right)$ are expressed as follows:

$$
\begin{aligned}
f_{i j}\left(x_{i j}, b_{i j}\right) & = \begin{cases}x_{i j}-b_{i j} & x_{i j}>b_{i j} \\
0 & -b_{i j} \leq x_{i j} \leq b_{i j} \\
x_{i j}+b_{i j} & x_{i j}<-b_{i j} \\
x_{i}-b_{d i} & x_{i}>b_{d i} \\
0 & \left.-x_{d i}, b_{d i}\right) \\
0 & x_{i} \leq b_{d i} \\
x_{i}+b_{d i} & x_{i}<-b_{d i} \\
y_{i}-b_{d i} & y_{i}>b_{d i} \\
0 & \left.-b_{d i} \leq y_{i} \leq b_{d i}\right) \\
y_{i}+b_{d i} & y_{i}<-b_{d i}\end{cases} \\
f_{z i}\left(z_{i}, b_{d i}\right) & = \begin{cases}z_{i}-b_{d i} & z_{i}>b_{d i} \\
0 & -b_{d i} \leq z_{1} \leq b_{d i} \\
z_{i}+b_{d i} & z_{i}<-b_{d i}\end{cases}
\end{aligned}
$$

where $x_{i j}$ is the relative vibration displacement.

Dynamic meshing force $F_{L i j}(L=\mathrm{I}$, II) can be expressed as follows:

$$
F_{L i j}=P_{L i j}+D_{L i j}=k_{i j} f_{i j}\left(x_{i j}, b_{i j}\right)+c_{i j} \dot{x}_{i j}
$$

The meshing damping $c_{i j}$ is calculated according to the following empirical formula (Dong et al., 2018):

$c_{i j}=2 \zeta_{g i j} \sqrt{\frac{k_{m i j}\left(I_{i} r_{b i}^{2} \cdot I_{j} r_{b j}^{2}\right)}{\left(I_{i} r_{b i}^{2}+I_{j} r_{b j}^{2}\right)}}$,

where $k_{m i j}$ is the average meshing stiffness. $\zeta_{g i j}$ is the damping coefficient. 


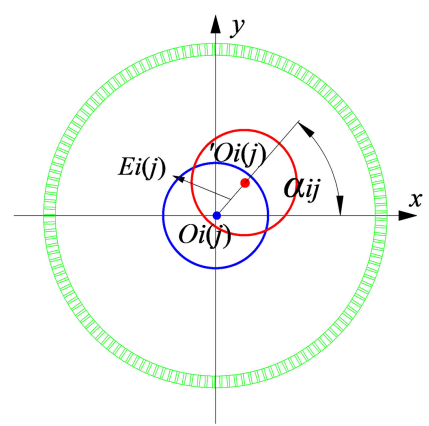

(a) I-stage face gear

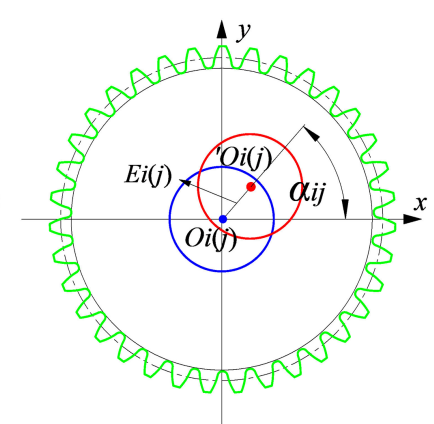

(b) II-stage cylindrical gear
Figure 6. Diagram of the eccentricity error.

Elastic force $P_{\mathrm{I} i j}$ and $P_{\mathrm{II} i j}$ as well as meshing damping force $D_{\mathrm{I} i j}$ and $D_{\mathrm{II} i j}$ can be expressed as follows:

$$
\left\{\begin{array}{l}
P_{\mathrm{I} i j}=k_{i j} f_{i j}\left(x_{i j}, b_{i j}\right)=k_{i j}\left(r_{b i} \varphi_{i}-r_{b j} \varphi_{j}\right. \\
+\left(z_{i}-z_{j}\right) \cos \alpha_{\mathrm{I} i j}+\left(y_{i}-y_{j}\right) \sin \alpha_{\mathrm{I} i j} \\
\left.-e(t)_{i j}, b_{i j}\right) \\
P_{\mathrm{II} i j}=k_{i j} f_{i j}\left(x_{i j}, b_{i j}\right)=k_{i j}\left(r_{b i} \varphi_{i}-r_{b j} \varphi_{j}\right. \\
+\left(x_{i}-x_{j}\right) \cos \alpha_{\mathrm{II} i j}+\left(y_{i}-y_{j}\right) \sin \alpha_{\mathrm{II} i j} \\
\left.-e(t)_{i j}, b_{i j}\right) \\
D_{\mathrm{I} i j}=c_{i j} \dot{x}_{i j}=c_{i j}\left(r_{b i} \dot{\varphi}_{i}-r_{b j} \dot{\varphi}_{j}\right. \\
+\left(\dot{z}_{i}-\dot{z}_{j}\right) \cos \alpha_{\mathrm{I} i j}+\left(\dot{y}_{i}-\dot{y}_{j}\right) \sin \alpha_{\mathrm{I} i j} \\
\left.-\dot{e}(t)_{i j}\right) \\
D_{\mathrm{II} i j}=c_{i j} \dot{x}_{i j}=c_{i j}\left(r_{b i} \dot{\varphi}_{i}-r_{b j} \dot{\varphi}_{j}\right. \\
+\left(\dot{x}_{i}-\dot{x}_{j}\right) \cos \alpha_{\mathrm{II} i j}+\left(\dot{y}_{i}-\dot{y}_{j}\right) \sin \alpha_{\mathrm{II} i j} \\
\left.-\dot{e}(t)_{i j}\right)
\end{array}\right.
$$

Here, $\alpha_{\mathrm{I} i j}$ is the positive angle between the meshing line and the center line of the one-stage face gear pair and the $z$ axis, $\alpha_{\mathrm{I} i j}(i=1, j=2,3)=-\pi / 2+\alpha_{n}+\gamma_{\mathrm{I} i j}$, and $\gamma_{\mathrm{I} i j}$ is the positive angle between the center line of the one-stage face gear pair and the $z$ axis. $\alpha_{\mathrm{II} i j}$ is the positive angle between the meshing line and the center line of the two-stage cylindrical gear pair and the $x$ axis, $\alpha_{I I i j}(i=4,5, j=6$, $7,8,9)=\pi / 2-\alpha_{n}+\gamma_{\mathrm{I} i j}, \alpha_{\mathrm{II} i j}(i=6,7,8,9, j=10)=$ $-\pi / 2+\alpha_{n}+\gamma_{i j}$, and $\gamma_{\mathrm{II} i j}$ is the positive angle between the center line of the two-stage cylindrical gear pair and the $x$ axis. $r_{b i}$ and $r_{b j}$ are the radius of base circle of gear $i$ and $j$.

The eccentricity errors of one-stage face gear and twostage cylindrical gear are shown in Fig. 6

Here, $O_{i(j)}$ is theoretical center position. ${ }^{\prime} O_{i(j)}$ is actual center position. $\alpha_{i j}$ is the angle between installation error and eccentricity error and $x$ axis.

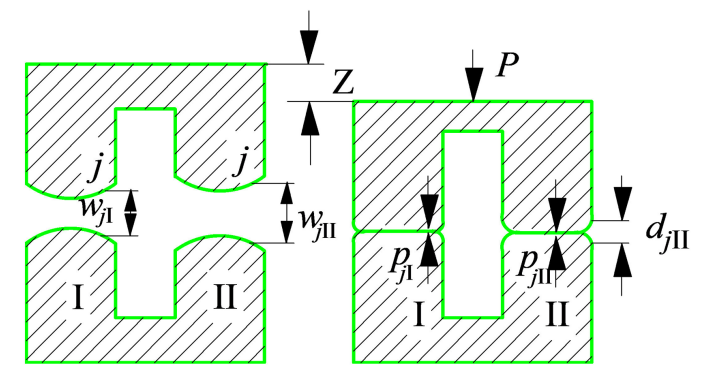

(a) I-stage face gear pair

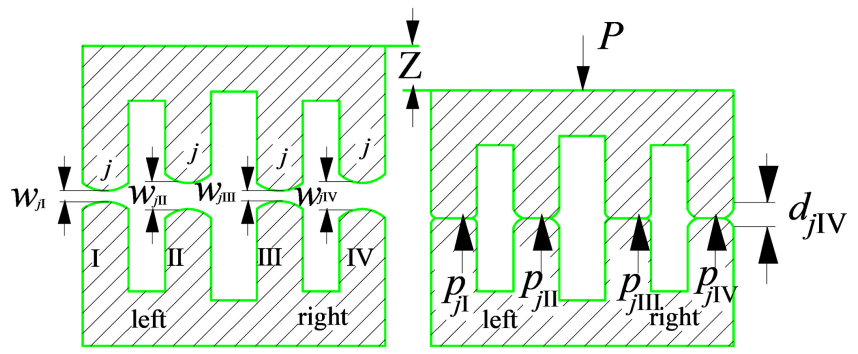

(b) II-stage gear pair

Figure 7. LTCA model of the one-stage face gear pair and twostage gear pair.

The equivalent meshing error $e(t)_{i j}$ can be expressed as follows:

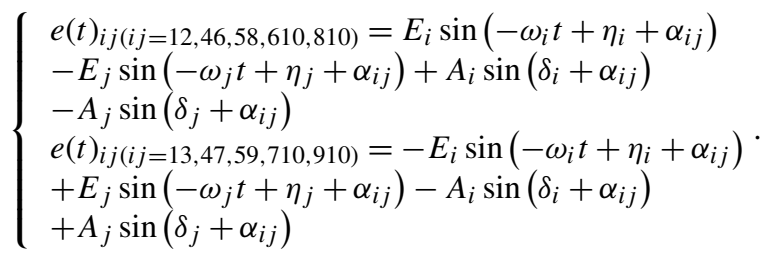

Here, $E_{i}$ and $E_{j}$ are eccentricity error. $A_{i}$ and $A_{j}$ are installation error. $\eta_{i}$ and $\eta_{j}$ are eccentricity error phase angle. $\delta_{i}$ and $\delta_{j}$ are installation error phase angle. $\omega_{i}$ and $\omega_{j}$ are excitation frequency.

The dimensionless time is defined as $\tau_{n}=\omega_{n} t$. Here, $\tau$ is the time variable of equations before dimensionless treatment. $\omega_{n}=\sqrt{\bar{k}_{12}\left(I_{1} r_{2}^{2}+I_{2} r_{1}^{2}\right) /\left(I_{1} I_{2}\right)} \cdot \bar{k}_{12}$ is the average meshing stiffness of one-stage gear pair. The displacement nominal scale $b_{c}$ is given. The dimensionless displacement, dimensionless velocity and dimensionless acceleration are expressed as $x_{i}=\bar{x}_{i} b_{c}, \dot{x}_{i}=\dot{\bar{x}}_{i} b_{c} \omega_{n}$ and $\ddot{x}_{i}=\ddot{\bar{x}}_{i} b_{c} \omega_{n}^{2}$, respectively. The backlash and support clearance are expressed as $b_{i j}=\bar{b}_{i j} b_{c}$ and $b_{d i}=\bar{b}_{d i} b_{c}$, respectively. Spline clearance is expressed as $R_{i}=\bar{R}_{i} b_{c}$. The dimensionless forms of excitation frequency are $\Omega_{i}=\omega_{i} / \omega_{n}, \Omega_{j}=\omega_{j} / \omega_{n}, \Omega_{b i}=$ $\omega_{b i} / \omega_{n}$ and $\Omega_{b j}=\omega_{b j} / \omega_{n}$, respectively. The dimensionless damping variable is $\bar{C}=c / 2 m w_{n}$, the dimensionless stiffness variable is $\bar{K}=k / m w_{n}^{2}$, and the dimensionless excitation force is $\bar{F}=F / m b_{c} w_{n}^{2}$.

The above-mentioned differential equations are normalized in dimension and solved by the Runge-Kutta method. 
Table 1. Gear parameters.

\begin{tabular}{lrrrrr}
\hline Gear & $\mathrm{O}_{1}$ & $\mathrm{O}_{2}, \mathrm{O}_{3}$ & $\mathrm{O}_{4}, \mathrm{O}_{5}$ & $\mathrm{O}_{6}, \mathrm{O}_{7}, \mathrm{O}_{8}, \mathrm{O}_{9}$ & $\mathrm{O}_{10}$ \\
\hline Tooth $z$ & 29 & 190 & 24 & 51 & 216 \\
Modulus (mm) & 3 & 3 & 4 & 4 & 4 \\
Tooth width $(\mathrm{mm})$ & 46 & 40 & 110 & 110 & 110 \\
Pressure angle $\alpha_{n}\left(^{\circ}\right)$ & 20 & 20 & 20 & 20 & 20 \\
Helix angle $\beta\left(^{\circ}\right)$ & 0 & 0 & 18 & 18 & 18 \\
Mass $m(\mathrm{~kg})$ & 12.67 & 96.32 & 13.26 & 45.69 & 980.6 \\
Moment of inertia $\mathrm{I}_{i}\left(\mathrm{~kg} \mathrm{~m}^{2}\right)$ & 0.091 & 1.032 & 0.104 & 0.426 & 11.68 \\
\hline
\end{tabular}

Table 2. Parameters of equivalent stiffness.

\begin{tabular}{ll}
\hline Stiffness & $\mathrm{N} \mathrm{mm} \mathrm{rad}-1$ \\
\hline Torsional stiffness of connecting shaft 24 & $k_{24}=4.82 \times 10^{6}$ \\
Torsional stiffness of connecting shaft 35 & $k_{35}=3.18 \times 10^{6}$ \\
Torsional stiffness of input shaft & $k_{\text {in }}=7.19 \times 10^{7}$ \\
Torsional stiffness of output shaft & $k_{\text {out }}=1.19 \times 10^{7}$ \\
Stiffness & $\mathrm{N} \mathrm{mm}^{-1}$ \\
Bending stiffness of connecting shaft 24 & $k_{w x 4}=k_{w y 4}=2.12 \times 10^{8}$ \\
Bending stiffness of connecting shaft 35 & $k_{w x 5}=k_{w y 5}=1.36 \times 10^{8}$ \\
One-stage face gear pair meshing stiffness & $k_{m 12}=k_{m} 13=0.85 \times 10^{6}$ \\
Two-stage pinion pair meshing stiffness & $k_{m 46}=k_{m 47}=k_{m 58}=k_{m 59}=0.46 \times 10^{7}$ \\
Two-stage gear pair meshing stiffness & $k_{m 610}=k_{m 710}=k_{m 810}=k_{m 910}=0.65 \times 10^{6}$ \\
Support stiffness of gear $O_{1}$ in $y, z$ direction & $k_{y 1}=k_{z 1}=2.86 \times 10^{8}$ \\
Support stiffness of gears $O_{2}, O_{3}$ in $y$ direction & $k_{y 2}=k_{y 3}=1.16 \times 10^{9}$ \\
Support stiffness of gears $O_{2}, O_{3}$ in $z$ direction & $k_{z 2}=k_{z 3}=5.86 \times 10^{8}$ \\
Support stiffness of gears $O_{6}, \ldots, O_{9}$ in $y$ direction & $k_{y 6}=k_{y 7}=k_{y 8}=k_{y 9}=3.66 \times 10^{8}$ \\
Support stiffness of gears $O_{6}, \ldots, O_{9}$ in $x$ direction & $k_{x 6}=k_{x 7}=k_{x 8}=k_{x 9}=2.09 \times 10^{8}$ \\
Support stiffness of gear $O_{10}$ in they direction & $k_{y 10}=4.82 \times 10^{9}$ \\
Support stiffness of gear $O_{10}$ in the $x$ direction & $k_{x 10}=5.12 \times 10^{9}$ \\
\hline
\end{tabular}

The DLSCs of $\Omega_{\mathrm{I}}$ and $\Omega_{\mathrm{II}}$ are obtained as follows:

$$
\left\{\begin{array}{rl}
\Omega_{\mathrm{I}} & =\max \left[\Omega_{12}, \Omega_{13}\right]=\max \left(\frac{\left(\bar{P}_{\mathrm{I} 12}, \bar{P}_{\mathrm{I} 13}\right)^{T}}{\frac{T_{\text {in }} / 2}{r_{1} \cos a_{n}}}\right) \\
\Omega_{\mathrm{II}} & =\max \left[\Omega_{610}, \Omega_{710}, \Omega_{810}, \Omega_{910}\right] \\
& =\max \left(\frac{\left(\bar{P}_{\mathrm{I} 610}, \bar{P}_{\mathrm{I} 710}, \bar{P}_{\mathrm{I} 810}, \bar{P}_{\mathrm{I} 910}\right)^{T}}{\left(\frac{T_{\text {in } / 2}}{r_{1} \cos a_{n} \cos \beta} I_{12} I_{46}\right) / 2}\right)
\end{array} .\right.
$$

Here, $\Omega_{\mathrm{I}}$ is the one-stage DLSC. $\Omega_{\mathrm{II}}$ is the two-stage DLSC. $\Omega_{i j}(i j=12,13,610, \ldots, 910)$ is the one-stage and two-stage DLSC of each branch. $\bar{P}_{\mathrm{I} i j}$ and $\bar{P}_{\mathrm{II} i j}$ are the average dynamic meshing force of each gear pair at one-stage and two-stage DLSC. $I_{12}$ and $I_{46}$ are the transmission ratio of gear pairs 12 and 46. The DLSC represents the load distribution of the system under the dynamic vibration response. The smaller the DLSC, the better the load-sharing performance of the system.

\section{Time-varying meshing stiffness calculation based on LTCA}

The loaded tooth contact analysis (LTCA) model of onestage face gear pair (Li and Zhu, 2010) and two-stage gear pair (Wang et al., 2010) is shown in Fig. 7. $j_{k}$ is a point along the relative principal direction, $k=1,2$ for one-stage face gear, $k=1,2,3,4$ for two-stage gear pair. Here, the tooth surface initial clearance $w$ is $[w]_{k}=[\delta]_{k}+[b]_{k}$. $[w]_{k}=\left[w_{1 k}, w_{2 k}, \ldots, w_{i k}, \ldots, w_{j k}, w_{n k}\right]^{T},[b]_{k}=\left[b_{1}, b_{2}\right.$, $\left.\ldots, b_{i}, \ldots, b_{n}\right]^{T}, n$ is the number of discrete points. $\delta$ is the geometric transmission error, $[\delta]_{k}=[1,1, \ldots, 1, \ldots, 1]^{T} . b_{j}$ is tooth surface normal clearance $(j=1, \ldots, n) . Z$ is the displacement direction.

Under the action of load $P$, the deformation coordination condition of the elastic deformation is as follows:

$$
\begin{aligned}
& (\mathbf{F})_{k}(p)_{k}+(w)_{k}=(Z)_{k}+(d)_{k}(k=\mathrm{I}, \mathrm{II}) \\
& \stackrel{\text { function }}{\longrightarrow}\left(\begin{array}{l}
(p)_{k}=\left(p_{1 k}, p_{2 k}, \ldots, p_{i k}, \ldots, p_{j k}, p_{n k}\right)^{T} \\
(Z)_{k}=(1,1, \ldots, 1, \ldots, 1)^{T} \\
(d)_{k}=\left(d_{1 k}, d_{2 k}, \ldots, d_{i k}, \ldots, d_{j k}, d_{n k}\right)^{T}
\end{array}\right) .
\end{aligned}
$$




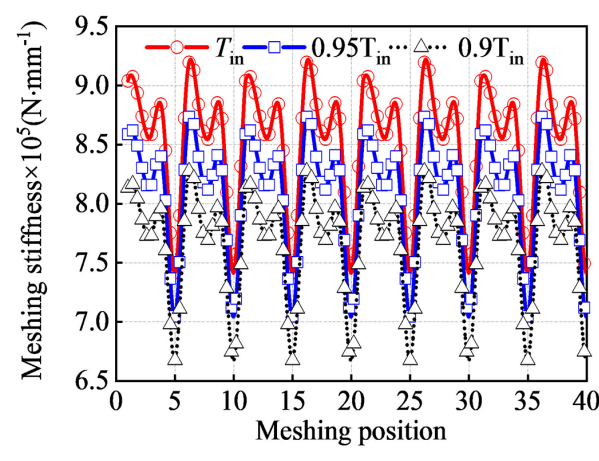

(a) I-stage face gear pairs

Figure 8. Time-varying meshing stiffness curve of each gear pair.

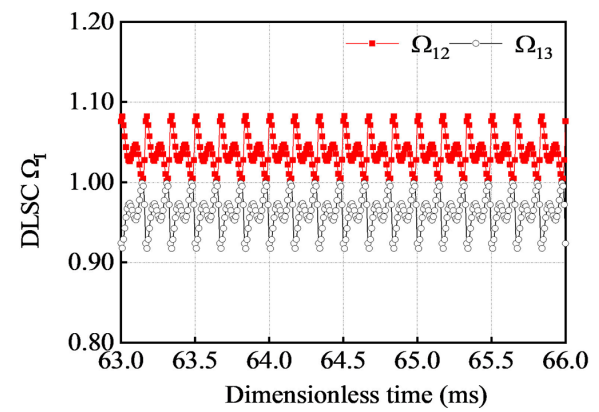

(a) I-stage DLSC

Figure 9. DLSC changed with dimensionless time.

$(\mathbf{F})_{k}$ is the normal flexibility coefficient matrix of the gear pair. $p_{j}(j=1,2, \ldots, n k)$ is the contact loaded at the point $j$ of the tooth $k$. Apparently, the contact force $p_{j}(j=$ $1,2, \ldots, n k)$ satisfies the following Eqs. (17)-(18):

$$
\left\{\begin{array}{l}
\sum_{j=1}^{n} p_{j \mathrm{I}}+\sum_{j=1}^{n} p_{j \mathrm{II}} \\
=p(\mathrm{I}-\text { stage face-gear pair }) \\
\sum_{j=1}^{n} p_{j \mathrm{I}}+\sum_{j=1}^{n} p_{j \mathrm{II}}+\sum_{j=1}^{n} p_{j \mathrm{III}}+\sum_{j=1}^{n} p_{j \mathrm{IV}} \\
=p(\mathrm{II}-\text { stage gear pair })
\end{array}\left(p_{j}(j=1,2, \ldots, n)\right) .\right.
$$

If $p_{j k}>0,[d]_{j k}=0$. If $[p]_{j k}=0,[d]_{j k}>0 . f, P$ and $w$ are known conditions. The contact forces $[p]_{j k}$, final backlash $[d]_{j k}$ and tooth approach $[Z]$ are unknown. The known parameters $(f, P, w)$ and unknown parameters $(p, d, Z)$ constitute a non-linear program model. According to the tooth approach $Z_{k}$, the objective function is established as follows:

$\operatorname{minimize}(p)^{T}\{(F)(p)+(w)-(Z)\}$.

The objective function equation can be expressed as follows:

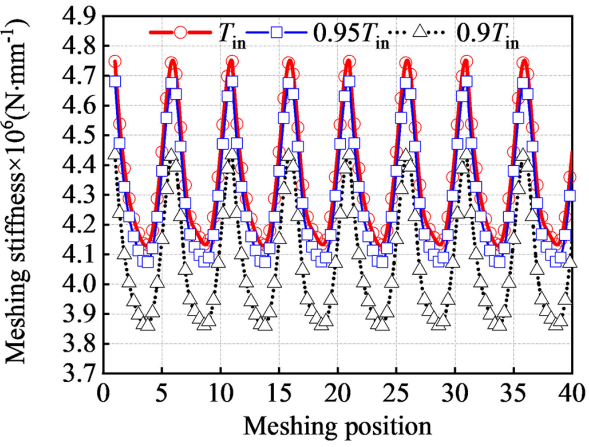

(b) II-stage herringbone gear pairs

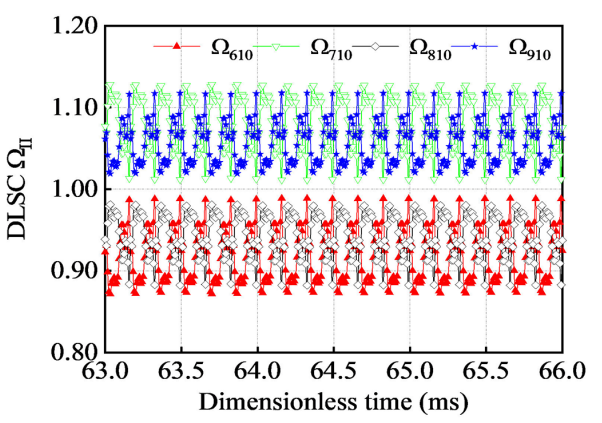

(b) II-stage DLSC

$X_{j}(j=1,2, \ldots, 2 n+1)$ is the artificial variables, $(X)=\left(X_{1}\right.$, $\left.\ldots, X_{2 n}\right)^{T},(e)=1$.

The transmission error of the gear bearing in meshing is mainly composed of three parts of the geometric transmission error $\delta_{1}$, the bending deformation $\delta_{2}$ and the contact deformation $\delta_{3}$. The geometric transmission errors $\delta_{1}$ can be expressed as $\delta_{1}(T(k))=a$. The bending deformation errors $\delta_{2}$ can be expressed as $\delta_{2}(T(k))=b T(k)$. The function relationship between the contact deformation $\delta_{3}(T(k))$ and the loaded $T(k)$ can be expressed as $\delta_{3}(T(k))=c T(k)^{2 / 3}$.

The relational expression of the integrated angular deformation $\Delta \varphi_{i j}\left(T_{i j}(k)\right)$ and torque $T_{i j}(k)$ of the gear pairs of the system can be expressed as follows: 
Table 3. Parameters of equivalent damping.

\begin{tabular}{ll}
\hline Damping & $\mathrm{N} \mathrm{mm} \mathrm{sad}-1$ \\
\hline Torsional stiffness of connecting shaft 24 & $c_{24}=2.12 \times 10^{4}$ \\
Torsional damping of connecting shaft 35 & $c_{35}=1.28 \times 10^{4}$ \\
Torsional damping of input shaft & $c_{\text {in }}=3.19 \times 10^{5}$ \\
Torsional damping of output shaft & $c_{\text {out }}=2.15 \times 10^{5}$ \\
Damping & $\mathrm{N} \mathrm{s} \mathrm{mm}^{-1}$ \\
Bending damping of connecting shaft 24 & $c_{w x 4}=c_{w x 5}=3.19 \times 10^{4}$ \\
Bending damping of connecting shaft 35 & $c_{w y 4}=c_{w y 5}=2.15 \times 10^{4}$ \\
One-stage face gear pair meshing damping & $c_{12}=c_{13}=3.34 \times 10^{4}$ \\
Two-stage pinion pair meshing damping & $c_{46}=c_{47}=c_{58}=c_{59}=4.61 \times 10^{4}$ \\
Two-stage gear pair meshing damping & $c_{610}=c_{710}=c_{810}=c_{910}=8.12 \times 10^{5}$ \\
Support damping of gear $O_{1}$ in $y, z$ direction & $c_{y 1}=c_{z 1}=1.13 \times 10^{4}$ \\
Support damping of gears $O_{2}, O_{3}$ in $y$ direction & $c_{y 2}=c_{y 3}=6.03 \times 10^{4}$ \\
Support damping of gears $O_{2}, O_{3}$ in $z$ direction & $c_{z 2}=c_{z 3}=3.66 \times 10^{4}$ \\
Support damping of gears $O_{6}, \ldots, O_{9}$ in $y$ direction & $c_{y 6}=c_{y 7}=c_{y 8}=c_{y 9}=2.17 \times 10^{4}$ \\
Support damping of gears $O_{6}, \ldots, O_{9}$ in $x$ direction & $c_{x 6}=c_{x 7}=c_{x 8}=c_{x 9}=1.96 \times 10^{4}$ \\
Support damping of gear $O_{10}$ in they direction & $c_{y 10}=6.60 \times 10^{5}$ \\
Support damping of gear $O_{10}$ in the $x$ direction & $c_{x 10}=9.16 \times 10^{5}$ \\
\hline
\end{tabular}

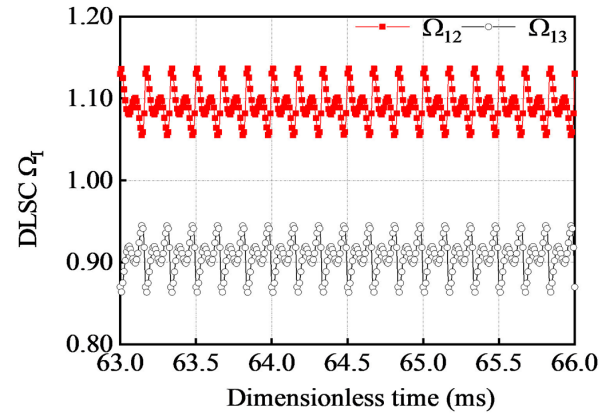

(a) I-stage DLSC

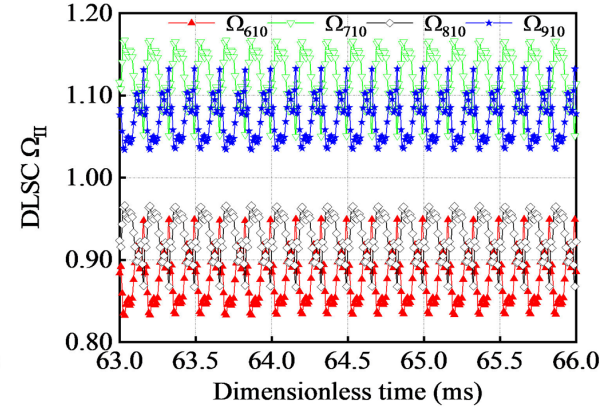

(b) II-stage DLSC

Figure 10. DLSC changed with dimensionless time.

$$
\begin{aligned}
\Delta \varphi_{i j}\left(T_{i j}(k)\right) & =\delta_{1}(T(k))+\delta_{2}(T(k))+\delta_{3}(T(k)) \\
& =\frac{T_{i j}(k)}{\left|T_{i j}(k)\right|}\left(a+b T_{i j}(k)+c T_{i j}(k)^{2 / 3}\right) .
\end{aligned}
$$

Here, $a, b$ and $c$ are the constant terms in the formula. $T_{i j}(k)$ is the torque of the $k$ th meshing position.

By solving the LTCA equations, the load transmission error $\Delta \varphi_{i j}\left[0.1 T_{i j}[k]\right], \Delta \varphi_{i j}\left[0.5 T_{i j}[k]\right]$ and $\Delta \varphi_{i j}\left[0.9 T_{i j}[k]\right]$ can be obtained. The coefficient $a, b$ and $c$ can be obtained by taking the obtained transmission error into Eq. (17).

The time-varying meshing stiffness $k_{i j}(k)$ can be obtained as follows:

$k_{i j}(k)=\frac{T_{i j}(k)}{r_{b i}^{2} \cos a_{n} \cos \beta_{i}} \cdot \frac{1}{\Delta \varphi_{i j}\left(T_{i j}(k)\right)}$.

\section{Example analysis}

Input power $P=2000 \mathrm{~kW}$, input speed $n=8780 \mathrm{rmin}^{-1}$, installation error $A_{i}=50 \mu \mathrm{m}$, eccentricity error $E_{i}=50 \mu \mathrm{m}$, and one-stage face gear backlash $b_{12}=b_{13}=10 \mu \mathrm{m}$. Twostage gear pair backlash $b_{610}=b_{710}=b_{810}=b_{910}=17 \mu \mathrm{m}$. Spline clearance $S_{2}=50 \mu \mathrm{m}$. Support clearance $b_{d i}=$ $10 \mu \mathrm{m}$. The gear parameters are shown in Table 1 .

The parameters of equivalent support stiffness, torsional stiffness and meshing stiffness are shown in Table 2. The support stiffness is calculated according to GB/T 3073-1996.

The parameters of equivalent supporting damping, torsional damping, and meshing damping are shown in Table 3.

The calculated time-varying meshing stiffness curve is shown in Fig. 8. The meshing stiffness fluctuation range of one-stage face gear pairs is $\left(7.46 \times 10^{5}\right.$ $\left.9.27 \times 10^{5}\right) \mathrm{N} \mathrm{mm}^{-1}$. The meshing stiffness fluctuation range of two-stage idler gear pairs is $\left(3.77 \times 10^{6}\right.$ 


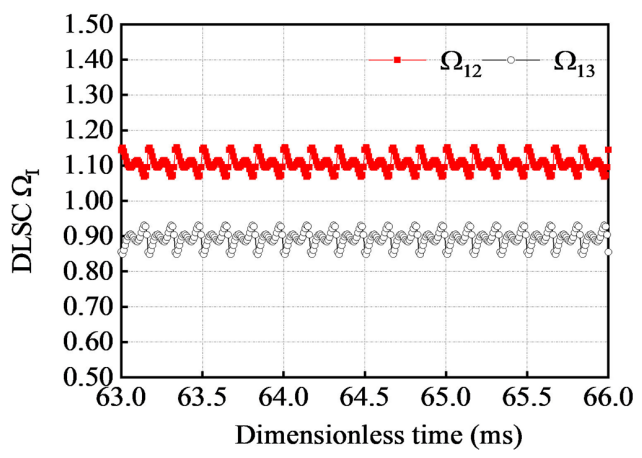

(a) I-stage DLSC

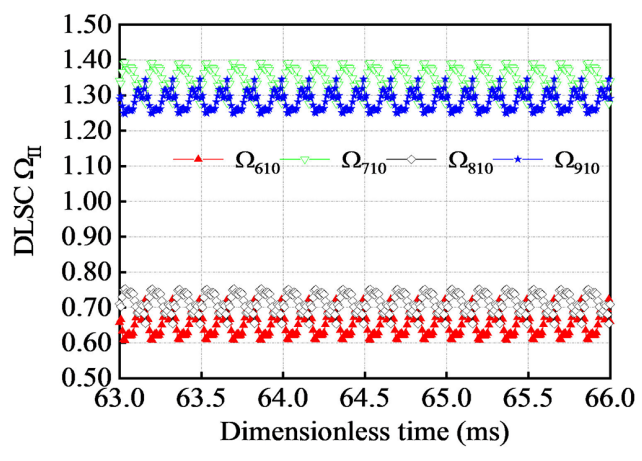

(b) II-stage DLSC

Figure 11. DLSC changed with dimensionless time.

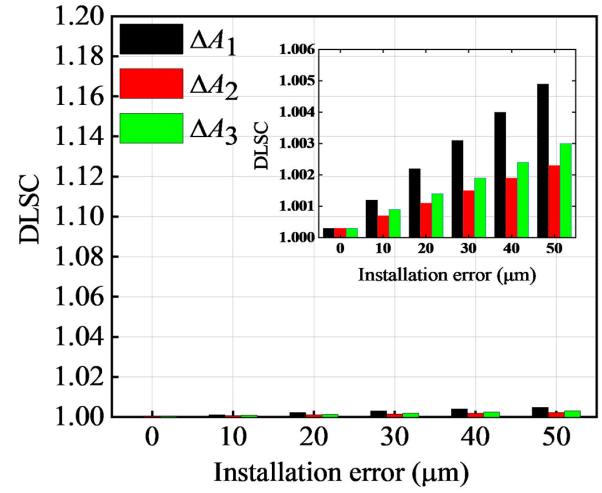

(a) I-stage DLSC

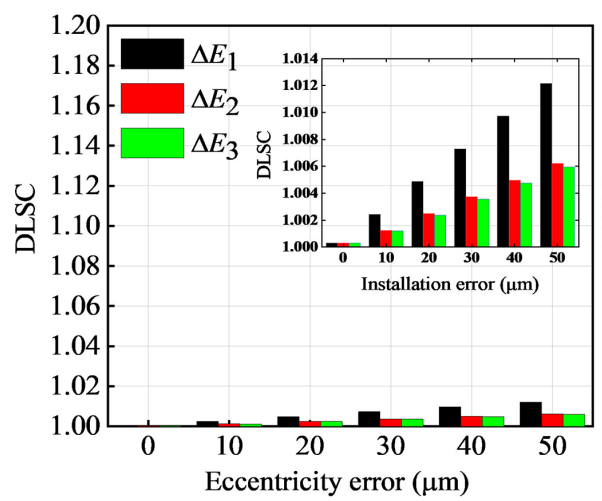

(c) I-stage DLSC

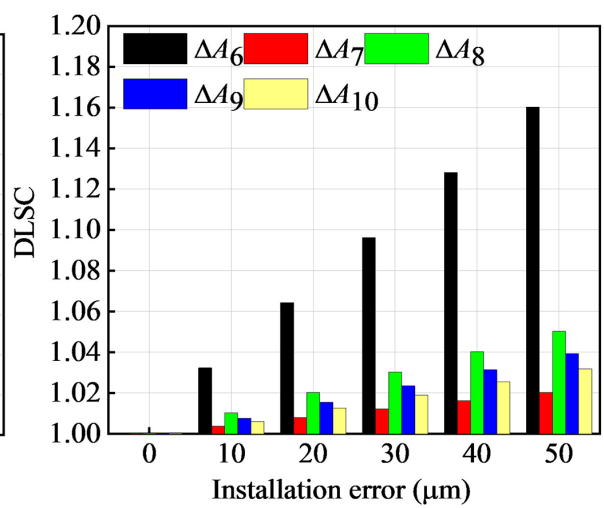

(b) II-stage DLSC

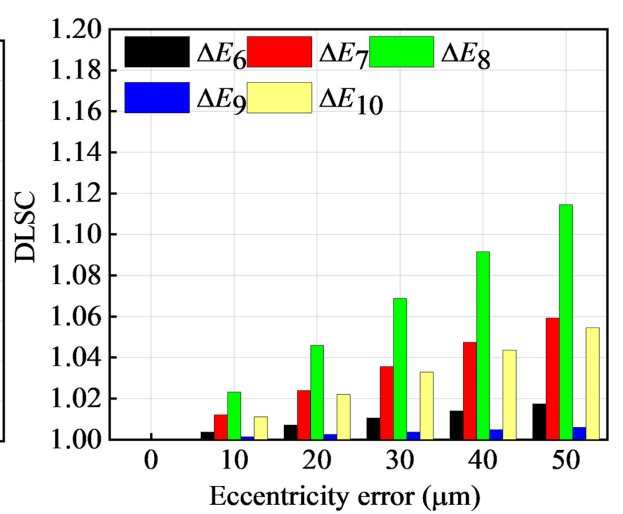

(d) II-stage DLSC

Figure 12. DLSC changed with installation and eccentricity error.

$\left.4.78 \times 10^{6}\right) \mathrm{N} \mathrm{mm}^{-1}$. The meshing stiffness fluctuation range of two-stage big gear pair is $\left(6.17 \times 10^{6}\right.$ $\left.6.68 \times 10^{6}\right) \mathrm{N} \mathrm{mm}^{-1}$. Due to the different meshing stiffness of each meshing position of the tooth surface, the DLSC of different meshing positions will be changed slightly.

\subsection{Effect of installation and eccentricity errors on the DLSC}

Under the combined action of installation error and eccentricity error, the DLSC presents periodic changes with time, as shown in Fig. 9. The one-stage DLSC is $\Omega_{12}=1.0383$ and $\Omega_{13}=0.9617$. Torque $T_{12}$ and $T_{13}$ are fluctuated around in 


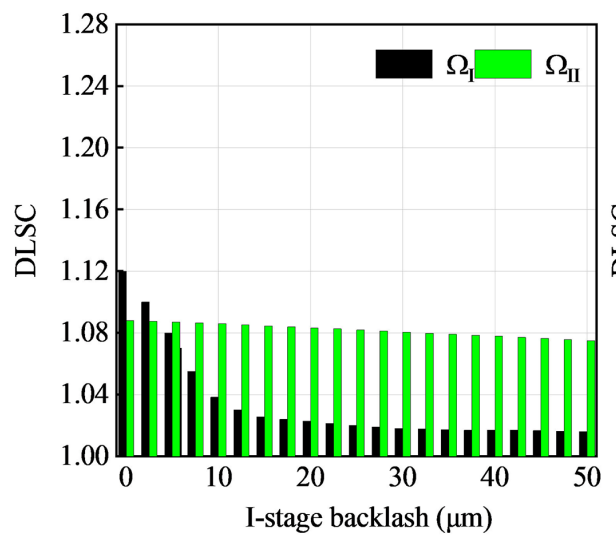

(a) I-stage DLSC

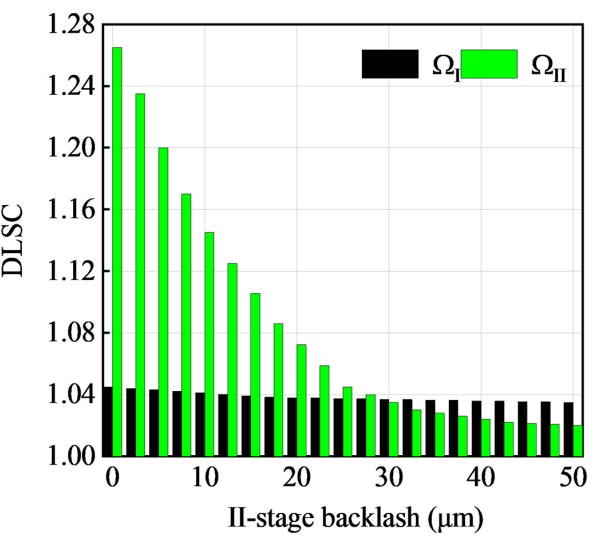

(b) II-stage DLSC

Figure 13. Influence of backlash on the DLSC.

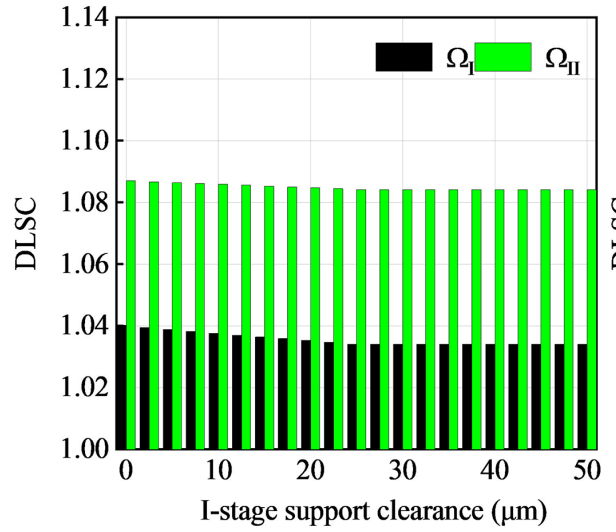

(a) I-stage DLSC

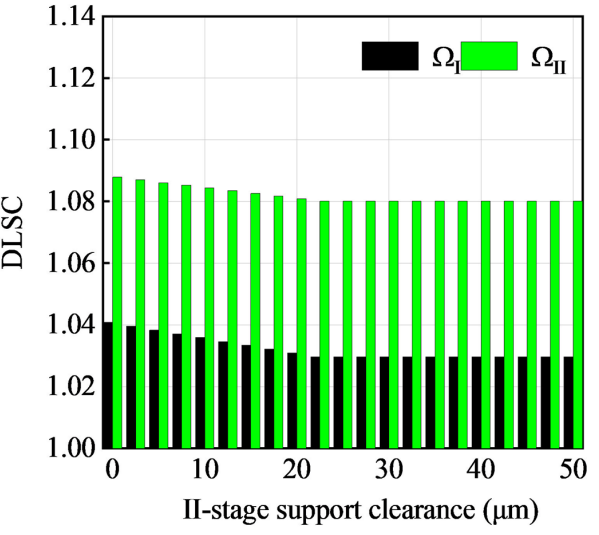

(b) II-stage DLSC

Figure 14. Influence of support clearance on the DLSC.

$1129.33 \mathrm{~N} \mathrm{~m}$ and $1046.0 \mathrm{~N} \mathrm{~m}$. Torque distribution is $51.92 \%$ and $48.09 \%$. The two-stage DLSC is $\Omega_{610}=0.914, \Omega_{710}=$ $1.086, \Omega_{810}=0.948$ and $\Omega_{910}=1.052$. Torque $T_{610}, T_{710}$, $T_{810}$ and $T_{910}$ are fluctuated around in $6920.5,8222.9,7178.1$ and $7965.4 \mathrm{Nm}$, respectively. The influence of one-stage gear pair 12 and two-stage gear pair 710 on the load-sharing characteristics is maximum impact. The overall DLSC is $\Omega_{Z}=1.086$. The DLSCs of the system are $\Omega_{\mathrm{I}}=1.0383$ and $\Omega_{\mathrm{II}}=1.0860$, respectively. The DLSC changed periodically with time.

Other parameters remain unchanged, when given $b_{12}=$ $b_{13}=0 \mu \mathrm{m}$. The DLSC under the combined action of errors is shown in Fig.10. The one-stage DLSCs of $\Omega_{\mathrm{I}}$ change from 1.0383 to 1.0921 . The two-stage DLSCs of $\Omega_{\text {II }}$ change from 1.0860 to 1.1220 . The one-stage face gear backlash has a great influence on the one-stage DLSC and a little influence on the two-stage DLSC.

Other parameters remain unchanged, when given onestage backlash $b_{12}=b_{13}=0 \mu \mathrm{m}$, two-stage backlash $b_{610}=$ $b_{710}=b_{810}=b_{910}=0 \mu \mathrm{m}$. The DLSC under the combined action of errors is shown in Fig. 11. The one-stage DLSCs of $\Omega_{\mathrm{I}}$ change from 1.0383 to 1.131 . The two-stage DLSCs of $\Omega_{\text {II }}$ change from 1.0860 to 1.3507 . Under the combined action of the errors, the load-sharing performance becomes worse with the decrease of the backlash.

The DLSC changes with the errors as shown in Fig. 12. Figure 12a and $\mathrm{b}$ show the influence of installation errors on the DLSC, and Fig. 12c and d show the influence of eccentricity errors on the DLSC. When the given error range is from $0-50 \mu \mathrm{m}$, the influence range of installation error on one-stage DLSC is 1.0003-1.0049, the influence range of installation error on two-stage DLSC is 1.0001-1.1605, the influence range of manufacturing error on one-stage DLSC is 1.0005-1.0125, and the influence range of manufacturing error on two-stage DLSC is 1.0005-1.1160. The installation errors and eccentricity errors have less influence on the onestage DLSC and more influence on the two-stage DLSC. The eccentricity errors are more sensitive than the installation errors on the one-stage DLSC. 


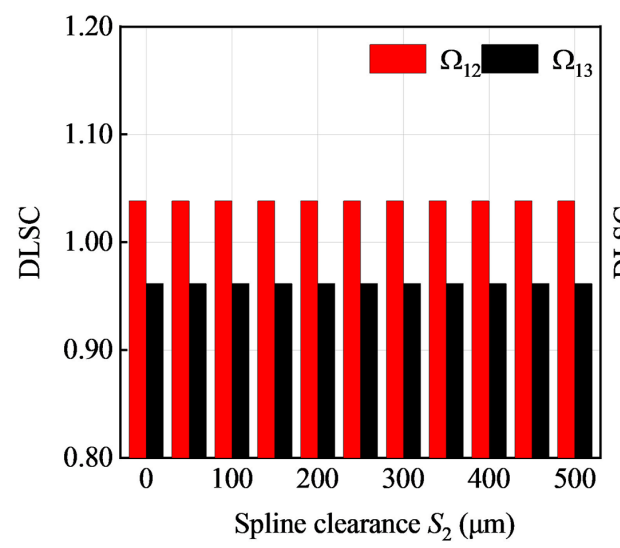

(a) I-stage DLSC

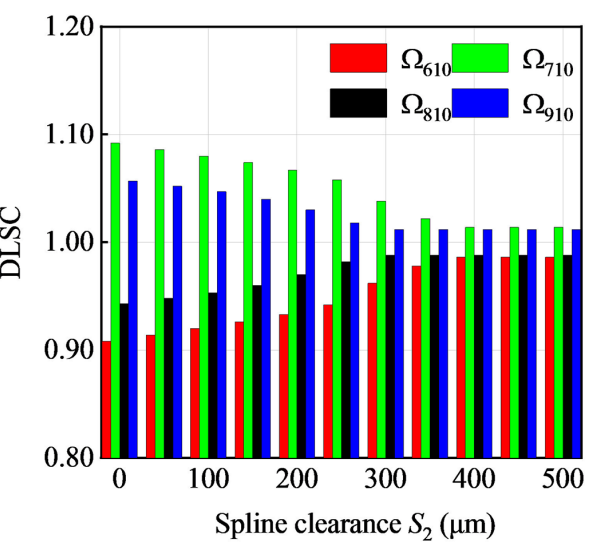

(b) II-stage DLSC

Figure 15. Load-sharing coefficient changed with the spline clearance.

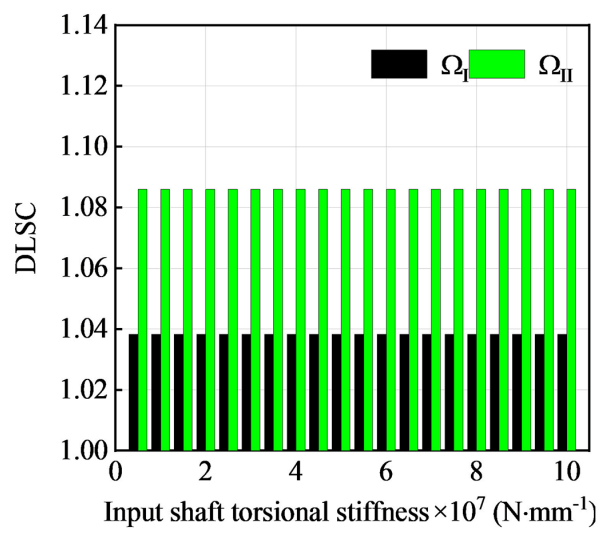

(a) input shaft torsional stiffness

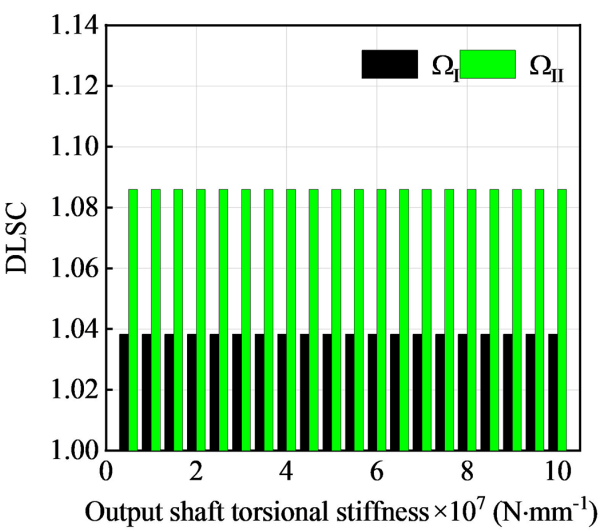

(b) output shaft torsional stiffness

Figure 16. Influence of input and output shaft torsional stiffness on dynamic load-sharing coefficient.

\subsection{Effect of backlash, support clearance and spline clearance on the DLSC}

The change of the DLSC $\Omega_{\mathrm{I}}$ and $\Omega_{\mathrm{II}}$ with the backlash is shown in Fig. 13. The one-stage DLSC $\Omega_{\mathrm{I}}$ changed strongly with the increase of one-stage backlash, which changed from 1.121-1.016. The influence of one-stage backlash on the two-stage DLSC $\Omega_{\text {II }}$ changes little, which changed from 1.088-1.075. The influence of two-stage backlash on twostage DLSC is more sensitive. With the increase of backlash, the DLSC gradually decreases from 1.268-1.021. The influence of two-stage backlash on one-stage DLSC is less, which changed from 1.045-1.035. In a certain range, the one-stage DLSC and two-stage DLSC decrease with the increase of the backlash. The backlash can compensate the deformation caused by the errors and improve the load-sharing performance to a certain extent.

When other parameters remain unchanged, the changes with the one-stage and two-stage DLSC support clearance and are shown in Fig. 14. With the increase of one-stage support clearance, the DLSC decreases gradually. $\Omega_{\mathrm{I}}$ changed from 1.0402-1.0341 and $\Omega_{\mathrm{II}}$ changed from 1.0870-1.0842. With the increase of two-stage support clearance, the DLSC $\Omega_{\mathrm{I}}$ decreased from 1.0408-1.0297, and $\Omega_{\mathrm{II}}$ decreased from 1.0879-1.0801. The influence of the support clearance on the DLSC is small.

Figure 15 shows the curves of one-stage and two-stage DLSC with the spline clearance from $0-450 \mu \mathrm{m}$. With the change of spline clearance, one-stage DLSC does not change at 1.0383, while two-stage DLSC changes from 1.09211.012. The influence of spline clearance on the one-stage DLSC is almost unchanged and has a great impact on the two-stage DLSC. When the spline clearance is $0 \mathrm{~mm}$, it is equivalent to the bending stiffness of the spline shaft to provide support. The DLSC is $\Omega_{610}=0.9079, \Omega_{710}=1.0921$, $\Omega_{810}=0.9432$ and $\Omega_{910}=1.0568$. When the spline clearance is greater than the total displacement $R_{5}(0.271 \mathrm{~mm})$, the two-stage pinion $O_{5}$ is in a fully floating state. When 


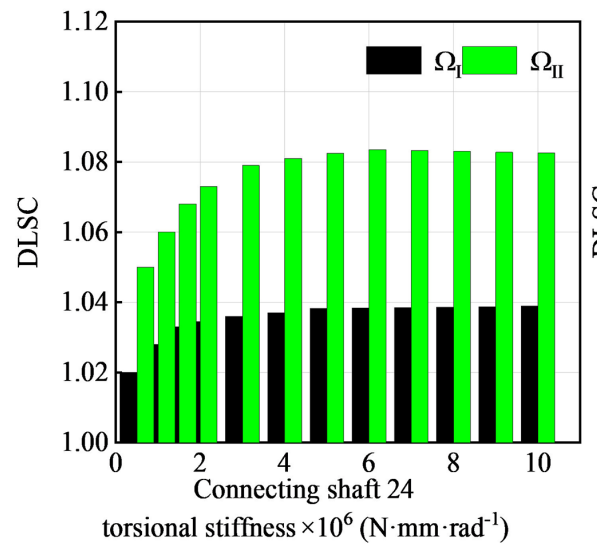

(a) Connecting shaft 24 torsional stiffness

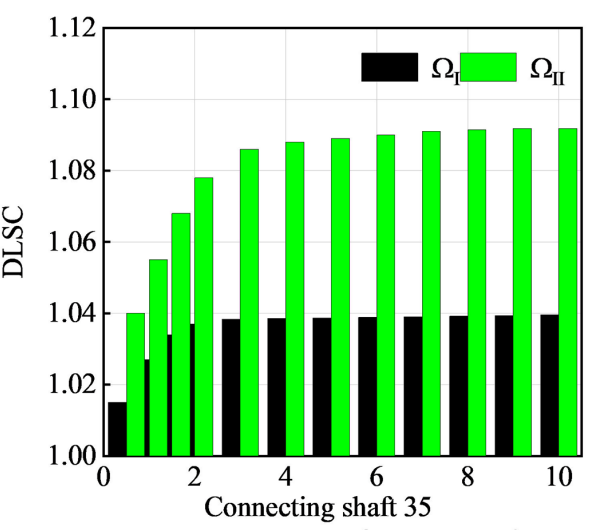

torsional stiffness $\times 10^{6}\left(\mathrm{~N} \cdot \mathrm{mm} \cdot \mathrm{rad}^{-1}\right)$

(b) Connecting shaft 35 torsional stiffness

Figure 17. Influence of torsional stiffness of connecting shaft on the dynamic load-sharing coefficient.

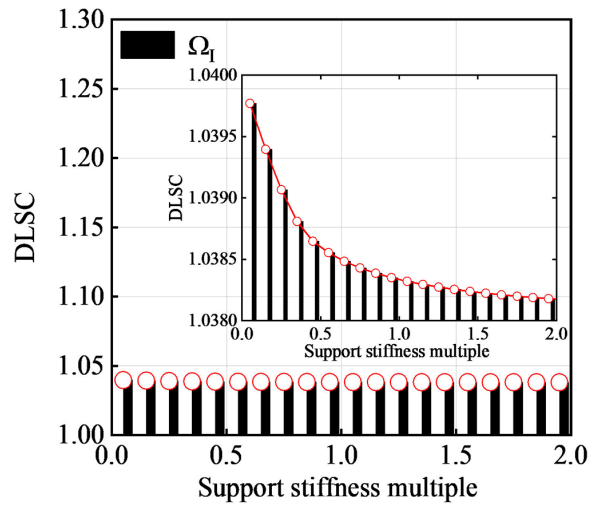

(a) I-stage DLSC

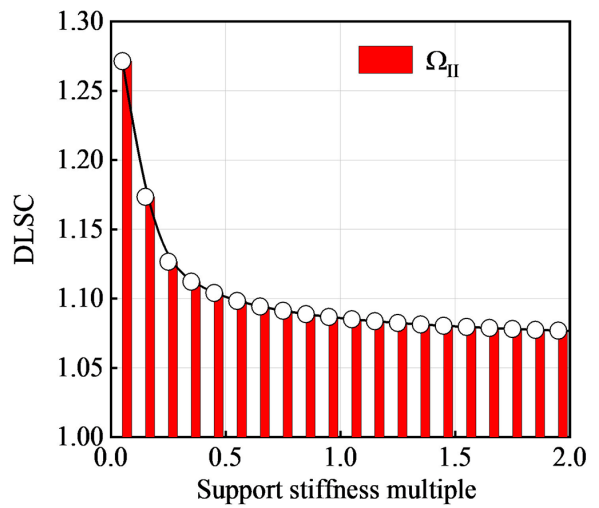

(b) II-stage DLSC

Figure 18. Influence of support stiffness on the dynamic load-sharing coefficient.

the spline clearance is greater than the total displacement $R_{4}(0.382 \mathrm{~mm})$, the two-stage pinion $\mathrm{O}_{4}$ and $\mathrm{O}_{5}$ enter a full floating state at the same time, and the load-sharing characteristic is improved, and the DLSC is stable at $\Omega_{\mathrm{II}}=$ 1.012. Among them, the DLSCs of two-stage gear pairs are $\Omega_{610}=0.9861, \Omega_{710}=1.0139, \Omega_{810}=0.988$ and $\Omega_{910}=$ 1.012. Two-stage pinion $\mathrm{O}_{4}$ and pinion $\mathrm{O}_{4}$ are independent in floating behavior.

\subsection{Effect of torsional stiffness and support stiffness on the DLSC}

The influence curve of DLSC of input shaft and output shaft is shown in Fig. 16 when the torsional stiffness changed from $(0.5-10.0) \times 10^{7} \mathrm{~N} \mathrm{~mm} \mathrm{rad}^{-1}$. Input shaft and output shaft have almost no influence on the dynamic load-sharing coefficient of the system. This conclusion is consistent with the conclusion of the influence of torsional stiffness on the load-sharing coefficient of power split transmission system analyzed in Jin et al. (2019a, b).

Other parameters remain unchanged, and the DLSC changes with the torsional stiffness of connecting shaft 24 and connecting shaft 35 at $(0.5-10.0) \times 10^{6} \mathrm{~N} \mathrm{~mm} \mathrm{rad}^{-1}$, as shown in Fig. 17. With the increase of the torsional stiffness of connecting shaft 24 and connecting shaft 35, the DLSC gradually becomes larger, the average load characteristics become worse, and the influence trend is the same. The influence of torsional stiffness on the two-stage DLSC is more obvious than that of the one-stage DLSC. Although the geometry of the system is symmetrical, but because of the different direction of meshing force and the geometry of the connecting axis, the force situation is not consistent, resulting in a certain difference in the dynamic load-sharing characteristics.

With other parameters unchanged, the overall support stiffness of each gear shown in Table 2 is (2-0.05) times that 
of the change, and the influence curve of the overall support stiffness on the DLSC of the system is shown in Fig. 18.

With the decrease of the support stiffness multiple, the DLSC becomes larger, and the dynamic performance becomes worse. Especially when the overall support stiffness multiple is (0.5-0.05), the influence of the dynamic loadsharing coefficient of two-stage DLSC is stronger, and the change of $\Omega_{\mathrm{II}}$ is from 1.0763-1.2714, but it has little influence on the dynamic load-sharing coefficient of one-stage DLSC, and the change of $\Omega_{\mathrm{I}}$ is from 1.0381-1.0397.

\section{Conclusions}

In this paper, a new configuration of face gear dual-power split transmission system is proposed, and the effects of backlash, support clearance, error, torsional stiffness and support stiffness on dynamic load-sharing characteristics are analyzed, which provides the theoretical basis for further optimization design of vibration stability. The conclusions are as follows:

1. With the increase of backlash, the DLSCs gradually decrease and tend to be stable. The two-stage DLSC has a great influence with the change of backlash. Increasing the backlash of each two-stage gear pair properly is conducive to improving the load-sharing characteristics. With the increase of the support clearance, the DLSC decreases, but the change value is small. The increase of the support clearance has little effect on the improvement of the dynamic load-sharing characteristics. The increase of spline clearance is beneficial to the improvement of even load characteristics.

2. With the increase of installation error and eccentricity error, the DLSC is larger and the system load-sharing performance is worse. The installation error and eccentricity error of each gear in level 2 have the greatest influence on the dynamic load-sharing coefficient. The installation and manufacture of each gear in level 2 should be considered in the design.

3. With the increase of torsional stiffness, the DLSC increases, and the load-sharing characteristics become worse. The change trend of the dynamic load-sharing coefficient is relatively consistent between the connecting shaft 24 and the connecting shaft 35 . In the optimal design of the load-sharing structure, the flexible connecting shaft meeting the strength should be selected to improve the load-sharing performance. With the decrease of support stiffness, the change two-stage DLSC is more intense. Choosing a reasonable rigid support in the optimal design is conducive to ensuring a better load-sharing performance.
Code and data availability. All data, models, and code generated or used during the study appear in the article.

Data availability. The raw/processed data required to reproduce these findings cannot be shared at this time as the data also form part of an ongoing study.

Author contributions. All authors contributed to the study conception and design. Material preparation, data collection and analysis were performed by HD, HQZ, XLZ and LLD. The first draft of the manuscript was written by HD, and all authors commented on previous versions of the manuscript. All authors read and approved the final manuscript.

Competing interests. The authors declare that they have no conflict of interest.

Financial support. This research has been supported by the National Natural Science Foundation of China (grant no. 51705390), the Innovation Capability Support Program of Shaanxi (grant no. 2020KJXX-016), the Scientific Research Program Funded by Shaanxi Provincial Education Department Program (grant no. 20JC015), the Principal Foundation Project of Xi' an Technological University (grant no. xgpy200201), and the Natural Science Foundation of Shaanxi Province (grant no. 2021JM-428).

Review statement. This paper was edited by Francisco Romero and reviewed by two anonymous referees.

\section{References}

Bao, H. Y., Li, F. B., and Lu, F. X.: Analysis of dynamic characteristics of a variable speed helicopter transmission system, Journal of Central South University (Science and Technology), 50, 2403-2416, https://doi.org/10.11817/j.issn.16727207.2019.10.009, 2019 (in Chinese).

Dong, H., Fang, Z. D., and Hu, Y. H.: Study on the load-sharing characteristics of an aeronautical II-stage five-branching planets gear train based on the loaded tooth contact analysis, Math. Probl. Eng., 5, 1-18, https://doi.org/10.1155/2018/5368294, 2018.

Dong, J. X., Tang, J. Y., and Hu, Z. H.: Investigation of assembly, power direction and load-sharing in concentric face gear split-torque transmission system, Meccanica, 54, 2485-2506, https://doi.org/10.1007/s11012-019-01078-0, 2019.

Handschuh, R. E., Lewicki, D. G., and Heath, G. F.: Experimental evaluation of face gears for aerospace drive system applications, San Diego, NASA Technical Memorandum, 107227, available at: https://www.researchgate.net/publication/24289872_ Experimental_Evaluation_of_Face_Gears_for_Aerospace Drive_System_Applications (last access: 20 May 2021), 1996. 
Heath, G. F. and Bossler, J. R. B.: Advanced rotorcraft transmission (ART) program-final report, Lewis, NASA Contractor Report, 191057, https://doi.org/10.2514/6.1991-1906, 1993.

Jin, G. H., Ren, W., and Zhu, R. P.: Influence of torsional stiffness on load-sharing characteristics of power split transmission system, J. Aerosp. Power, 34, 2478-2489, https://doi.org/10.13224/j.cnki.jasp.2019.11.020, 2019a (in Chinese).

Jin, G. H., Ren, W., and Zhu, R. P.: Influence of backlash on load-sharing and dynamic load characteristics of twice split torque transmission system, J. Vib. Eng. Technol., 7, 565-577, https://doi.org/10.1007/s42417-019-00150-z, 2019 b.

Krantz, T. L.: A method to analyze and optimize the load-sharing of split path transmissions, NASA Technical Memorandum, 107201, available at: https://www.researchgate.net/ publication/24290120_A_Method_to_Analyze_and_Optimize_ the_Load_Sharing_of_Split_Path_Transmissions (last access: 20 May 2021), 1996a.

Krantz, T. L. and Delgado, I. R.: Experimental study of split-path transmission load-sharing, NASA Technical Memorandum, 107202, available at: https://ntrs.nasa.gov/citations/ 19960035852 (last access: 20 May 2021), 1996 b.

Li, Z. M. Q. and Zhu, R. P.: Load tooth contact analysis on face-gear driver, Journal of Nanjing University of Aeronautics \& Astronautics, 42, 219-223, https://doi.org/10.16356/j.10052615.2010.02.007, 2010 (in Chinese).

Mo, S., Yue, Z. X., and Feng, Z. Y.: Analytical investigation on load-sharing characteristics for multi-power face gear split flow system, P. I. Mech. Eng. C, 234, 095440621987695, https://doi.org/10.1177/0954406219876954, 2019.

Peng, M., Desmidt, H. A., Saribay, Z. B., and Smith, E. C.: Parametric instability of face-gear drives due to meshing loads, J. Am. Helicopter. Soc., 61, 1-13, https://doi.org/10.4050/JAHS.61.042006, 2016.
Robert, F. H. and James, J. Z.: Current research activities in drive system technology in support of the NASA rotorcraft program, NASA Technical Memorandum, 214052, available at: https://www.researchgate.net/publication/289464290_Current_ research_activities_in_drive_system_technology_in_support_ of_the_NASA_rotorcraft_program (last access: 20 May 2021), 2006.

Stevens, M. A., Handschuh, R. F., and Lewicki, D. G.: Variable/Multispeed rotorcraft drive system concepts, NASA Technical Memorandum, 215456, available at: https://ntrs.nasa.gov/ citations/20090019132 (last access: 20 May 2021), 2009.

Wang, C., Fang, Z. D., and Gu, J. G.: Loaded tooth contact analysis of double helical gears and experimental investigation, J. Aerosp. Power, 25, 718-722, https://doi.org/10.13224/j.cnki.jasp.2010.03.005, $2010 \quad$ (in Chinese).

Wang, Q. B., Tang, J. Y., and Tan, W. Z.: Load-sharing performance of two branches split-torque transmission system with cylindrical gears, J. Aerosp. Power, 34, 1598-1606, https://doi.org/10.13224/j.cnki.jasp.2019.07.021, 2019 (in Chinese).

Wang, R. F., Zhao, N., and Tao, L.: Floating shaft loadsharing method for face-gear split torque transmission system, Res. J. Appl. Sci. Eng. Technol., 5, 3386-3392, https://doi.org/10.19026/rjaset.5.4584, 2013.

Zhang, L. L. and Zhu, R. P.: Static load-sharing behavior of herringbone planetary gear train with floating composite ring gear, Journal of Central South University (Science and Technology), 49, 1126-1134, https://doi.org/10.11817/j.issn.16727207.2018.05.014, 2018 (in Chinese). 